NATIONAL AERONAUTICS AND SPACE ADMINISTRATION

Technical Report No. 32-827

\title{
Tensile Behavior of Same-Lot Single-Crystal and Polycrystalline Tungsten from 2500 to $5000^{\circ} \mathrm{F}$
}

Jack L. Taylor

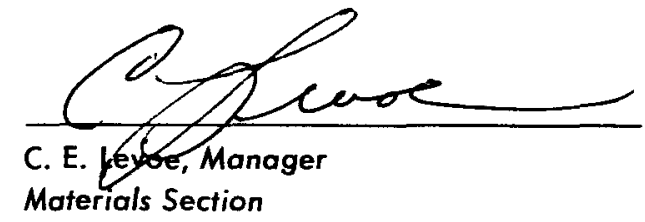

JET PROPULSION LABORATORY CALIFORNIA INSTITUTE OF TECHNOLOGY PASADENA, CALIFORNIA November 15, 1965 
Copyright (C) 1965

Jet Propulsion Laboratory

California Institute of Technology

Prepared Under Contract No. NAS 7.100

National Aeronautics \& Space Administration 


\section{CONTENTS}

I. Introduction . . . . . . . . . . . . . . . . . . . . 1

II. Experimental Procedure . . . . . . . . . . . . . . . . 1

A. Material and Heat Treatment . . . . . . . . . . . . . . . . . 1

B. Orientation Determination . . . . . . . . . . . . . . . 2

C. Tensile Apparatus . . . . . . . . . . . . . . . . . . . . 2

III. Results . . . . . . . . . . . . . . . . . . . . . . . . 3

A. Single-Crystal Data . . . . . . . . . . . . . . . . . . 3

1. Preferred Orientation . . . . . . . . . . . . . . . . 3

2. Slip Systems . . . . . . . . . . . . . . . . . . . 4

3. Stress-Strain Curves . . . . . . . . . . . . . . . . 4

4. Elongation . . . . . . . . . . . . . . . . . . . 7

5. Maximum True Stress . . . . . . . . . . . . . . . . 8

6. Resolved Yield Stress . . . . . . . . . . . . . . . . . . 9

7. Microstructure . . . . . . . . . . . . . . . . . . 9

B. Polycrystalline Tungsten . . . . . . . . . . . . . . . . 10

1. Elongation and Reduction in Area . . . . . . . . . . . . 10

2. Maximum True Stress . . . . . . . . . . . . . . . . 11

3. Cooling Rate . . . . . . . . . . . . . . . . . . . 11

IV. Conclusions . . . . . . . . . . . . . . . . . . . . . . . . . 12

References . . . . . . . . . . . . . . . . . . . . . . . . . . . . . 12

\section{TABLE}

1. Chemical analysis of MK tungsten . . . . . . . . . . . . . . . . . . . . . . 2

\section{FIGURES}

1. Head of tungsten tensile specimen showing single-crystal core.

View parallel to tensile axis

2. Orientation of tensile axes of fungsten single-crystal specimens . . . . 3

3. Unit friangle showing $(a)$ regions of preferred slip for three families of slip, $\{110\}<111\rangle,\{112\}<111\rangle$, and $\{123\}<111\rangle$, in bec metals calculated from critical resolved shear stresses (Refs. 11, 12), (b) experimentally determined slip directions. . . . . . 4

4. Engineering stress-strain curves for fungsten single crystals deformed at $2500^{\circ} \mathrm{F}$ in tension . . . . . . . . . . . . . . . . . . . . . 5 


\section{FIGURES (Cont'd)}

5. Engineering stress-strain curves for tungsten single crystals deformed at $4500^{\circ} \mathrm{F}$ in tension . . . . . . . . . . . . . . . . . . . . 6

6. Specimen 1-17 showing knife-edge failure and second neck . . . . . 7

7. Elongation of single-crystal tungsten as a function of temperature for orientations centered about latitude $=3 \mathrm{deg}$ and

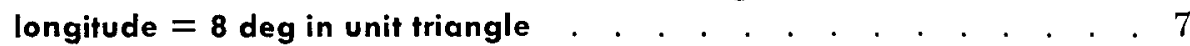

8. Elongation of single-crystal tungsten as a function of temperature for orientations centered about latitude $=3 \mathrm{deg}$ and longifude $=20 \mathrm{deg}$ in unit triangle

9. Elongation of single-crystal tungsten as a function of temperature for orientations centered about latitude $=3 \mathrm{deg}$ and longitude $=\mathbf{2 9} \mathrm{deg}$ in unit triangle.

10. Elongation of single-crystal tungsten as a function of temperature for orientations centered about latitude $=14 \mathrm{deg}$ and longitude $=22 \mathrm{deg}$ in unit triangle

11. Maximum true stress of single-crystal tungsten as a function of temperature for orientations centered on latitude $=3 \mathrm{deg}$ and longitude $=8 \mathrm{deg}$, latitude $=3 \mathrm{deg}$ and longitude $=20 \mathrm{deg}$, and latitude $=3 \mathrm{deg}$ and longitude $=29 \mathrm{deg}$ in unit triangle .

12. Longitudinal sections of specimens tested to failure: (a) crystal 2-4 tested at $3500^{\circ} \mathrm{F}$, (b) crystal 2-10 tested at $4000^{\circ} \mathrm{F}$,

(c) crystal 1-17 tested at $4500^{\circ} \mathrm{F}$. Etched $1 \mathrm{~min}$ in $30 \mathrm{~cm}^{3}$ lactic acid, $10 \mathrm{~cm}^{3} \mathrm{HNO}_{3,}$ and $10 \mathrm{~cm}^{3} \mathrm{HF}$...$\quad$. . . . . . . . . . . . . . . 9

13. Elongation of polycrystalline tungsten as a function of temperature . . . 10

14. Reduction in area of polycrystalline fungsten as a function of temperature... . . . . . . . . . . . . . . . . . . . 10

15. Maximum true stress and ultimate tensile strength of polycrystalline fungsten as a function of temperature . . . . . . . . . . . . . . . 11 


\section{ABSTRACT}

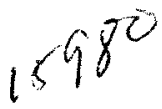

The tensile properties of single-crystal tungsten produced by annealing commercial type-MK powder-metallurgy rod at $5150^{\circ} \mathrm{F}$ were studied at a nominal strain rate of $0.02 / \mathrm{min}$ as a function of orientation and tempcrature $\left(2500\right.$ to $\left.5000^{\circ} \mathrm{F}\right)$. A preferred orientation was exhibited by the crystals, the tensile axes of over $75 \%$ of them being oriented between $\simeq 10$ and $\simeq 30 \mathrm{deg}$ from the [001] corner of the unit triangle. Single crystals within $\simeq 19 \mathrm{deg}$ of the $[001]$ corner, oriented for $\{112\}$ $<111\rangle$ and $\{123\}<111>$ family slip, were the strongest up to $\simeq 4000^{\circ} \mathrm{F}$ and the most ductile at all temperatures in the test range. $\mathrm{A}$ minimum at $\simeq 4000^{\circ} \mathrm{F}$ and a maximum at $\simeq 4500^{\circ} \mathrm{F}$ occurred in curves of elongation vs. temperature for single crystals whose orientations were in the region of $\{110\}<111>$ family slip $\simeq 20$ to $\simeq 30 \mathrm{deg}$ from the $[001]$ corner, a region in which over $50 \%$ of the single crystals were oriented. Little if any variation with orientation was observed in values of resolved yield stress, which ranged from $1000 \pm 150$ psi at $2500^{\circ} \mathrm{F}$ to $500 \pm 50$ psi at $500^{\circ} \mathrm{F}$.

Polycrystalline tungsten of the same lot and chemical composition as the single-crystal material also was tested under the same conditions of strain rate and temperature. The tensile results were consistent with results previously reported by the author for other lots of polycrystalline powder-metallurgy tungsten, including a ductility minimum at $\simeq 3500^{\circ} \mathrm{F}$ and a maximum at $\simeq 4500^{\circ} \mathrm{F}$. It appears that orientation may be a factor in the ductility minimum in polycrystalline tungsten, presuming that the many small crystals making up the core of the polycrystalline specimens exhibit the same preferred orientation as the single-crystal material. The maximum in elongation which also occurs in both polycrystalline and single-crystal tungsten may be similarly related through preferred orientation. Comparison of polycrystalline and single-crystal tungsten indicated an upper limit of $\simeq 2-1$ to the strengthening effect due to grain size at $2500^{\circ} \mathrm{F}$ and above.

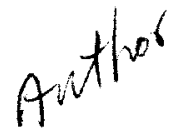




\section{INTRODUCTION}

The present investigation was undertaken to study the deformation behavior of single-crystal powder-metallurgy tungsten as a function of orientation and temperature.

Measurements of tensile properties of crystals oriented between $\simeq 6$ and $\simeq 30$ deg from the [001] corner of the unit triangle were made from 2500 to $5000^{\circ} \mathrm{F}$ in vacuum at a nominal strain rate of $0.02 / \mathrm{min}$. Polycrystalline tungsten of the same lot and chemical composition as the single-crystal material also was tested under the same conditions of temperature and strain rate.
No data on the very high-temperature properties of single-crystal tungsten have been available, to the author's knowledge. Electron beam-melted single crystals of tungsten (Ref. 1) have been investigated recently up to $1500^{\circ} \mathrm{F}$, and rolling deformation studies of plasma-flame singlecrystal tungsten (Ref. 2 ) have been made at $1800^{\circ} \mathrm{F}$. Knowledge of the behavior of tungsten in single-crystal form might be expected to shed light on phenomena such as the ductility minimum (Refs. 3-6) in polycrystalline powdermetallurgy tungsten rod, and the ductility maximum(Ref.5) at $\simeq 4500^{\circ} \mathrm{F}$ in several lots of polycrystalline tungsten.

\section{EXPERIMENTAL PROCEDURE}

\section{A. Material and Heat Treafment}

Powder-metallurgy tungsten, MK type, was obtained commercially as a single 100 -lb lot in the form of 716 -in.-dia swaged rods four to five $\mathrm{ft}$ in length. Potassium, aluminum, and silicon had been added to the tungsten powder in amounts less than required for making "nonsag" wire for lamp filaments before pressing and sintering. The doping additives, although present only as residual traces after sintering, raised the recrystallization temperature.

Standard tensile specimens of the R-4 type (Ref. 7), 0.640 -in. gage length by 0.160 -in. dia, were ground from 1.7-in.-long segments cut consecutively from one end of a rod to the other. Two-inch segments were removed from each end and a half-inch segment was cut after every third specimen for chemical analysis.

Prior to testing, specimens were heated in groups of six to eight for ten minutes at $5150^{\circ} \mathrm{F}$ in vacuum of $1 \times 10^{-5}$ torr or less. Some of the specimens exhibited unusual recrystallization behavior. In each group, a few specimens grew single-crystal cores large enough to encompass the whole length and gage diameter, and the orientation of the crystal was the same throughout the length. Of the specimens made from rod $M \mathrm{~K} 1$, all but one developed single-crystal cores of various orientations.

The single-crystal core of specimen 1-14 (specimen No. 14 from rod $\mathrm{MK} 1$ ) is shown as an example in Fig. 1.
Small grains encapsulated in the single-crystal matrix are evident. However, Laue back-reflection x-ray photographs which generally showed sharp spots indicated fair crystal perfection.

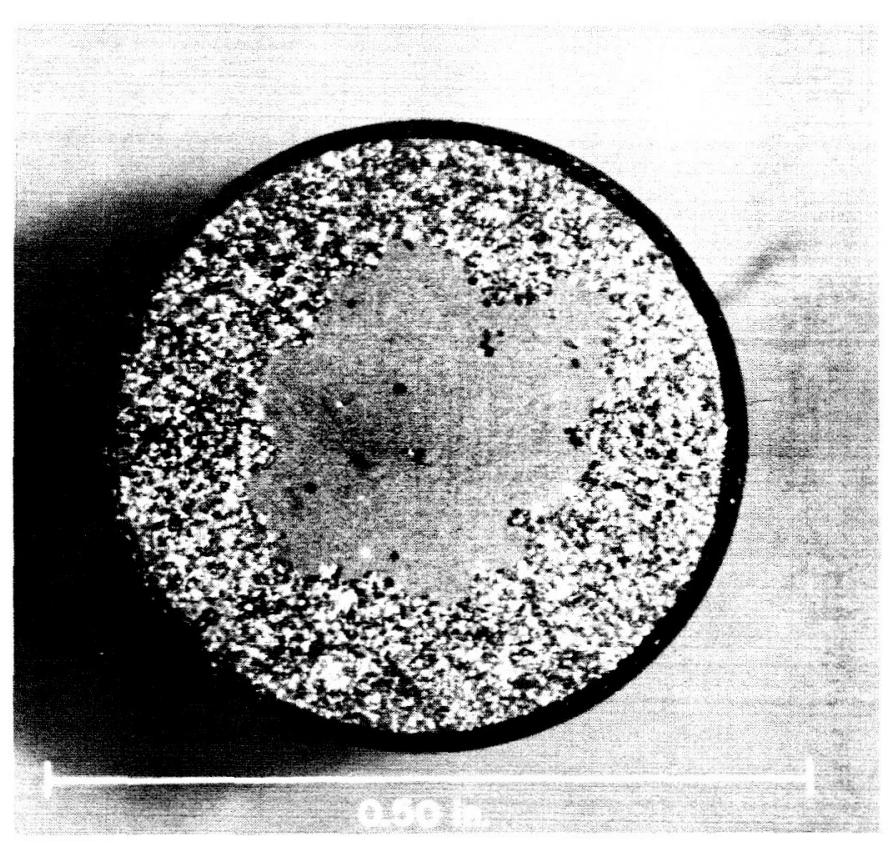

Fig. 1. Head of tungsten tensile specimen showing single-crystal core. View parallel to tensile axis 
Specimens were subjected to two rates of cooling from the recrystallization temperature, $\simeq 12$ and $\simeq 280^{\circ} \mathrm{F} / \mathrm{sec}$. In the first case the specimen was cooled in the furnace and in the second it was quenched by rapid removal from the hot zone. Furnace-cooled polycrystalline specimens had an average grain size of 307 grains $/ \mathrm{mm}^{2}(0.057 \mathrm{~mm}$ dia) and quenched specimens, 276 grains $/ \mathrm{mm}^{2}(0.06 \mathrm{~mm}$ dia). Grain size was measured on photomicrographs taken at $100 \times$ by the Heyn intercept method.

Impurity levels in the powder-metallurgy tungsten, determined by a commercial laboratory, are given in Table 1. One analysis of rod MK4 "as received" made by an independent laboratory using advanced experimental techniques showed silicon, $35 \mathrm{ppm}$; aluminum, $14 \mathrm{ppm}$; chlorine, $8 \mathrm{ppm}$; sulfur, $2 \mathrm{ppm}$; and potassium, $1 \mathrm{ppm}$. No analysis in this case was made for oxygen, nitrogen, or carbon. The "as received" rods were of good purity for commercial tungsten, and the level of impurity was reduced by the recrystallization treatment in vacuum. In specimens which had single-crystal cores, separate analy-

Table 1. Chemical analysis of MK tungsten"

\begin{tabular}{|c|c|c|c|c|c|}
\hline \multirow{2}{*}{ Material } & \multirow{2}{*}{ Condition } & \multicolumn{4}{|c|}{ Parfs per million by weight } \\
\hline & & 0 & H & c & $\mathbf{N}$ \\
\hline MKI & "As received" rod & $10.4-13.2$ & $0.1-0.4$ & $12-15$ & $5-8$ \\
\hline MK3 & "As received" rod & $17.2-24.4$ & $0.3-0.6$ & $8-15$ & $3-5$ \\
\hline MK5 & "As received" rod & $12.9-20.0$ & $0.3-0.4$ & $7-13$ & $5-18$ \\
\hline MK3-17 & Recrystallized specimen & 4.7 & 0.3 & 7.0 & 4.0 \\
\hline MK5-20 & Recrystallized specimen & 3.2 & 0.1 & 7.0 & 6.0 \\
\hline \multicolumn{6}{|c|}{$\begin{array}{l}\text { "In oddition spectrographic analysis was made for } \mathrm{Fe}, \mathrm{Ni}, \mathrm{Si}, \mathrm{Al} \text {, and } \mathrm{Mo} \text {. In the } \\
\text { "as-received" rod, } \mathrm{Ni} \text {, Al, and Mo were not detected, i.e. }<10 \mathrm{ppm} \text {; wnile } \\
\mathrm{Fe} \text { and } \mathrm{Si} \text { were detected in amounts of } \simeq 10 \mathrm{ppm} \text {. After heot treatment } \mathrm{Fo} \\
\text { and } \mathrm{Si} \text { were }<10 \mathrm{ppm} \text {. } \\
\text { bSingle crystal core. }\end{array}$} \\
\hline
\end{tabular}

sis of the polycrystalline outer section and the core was not attempted.

\section{B. Orientation Determination}

Orientation of the tensile axes of the tungsten single crystals was determined by optical reflection from $\{110\}$ planes. The $\{110\}$ planes were preferentially etched electrolytically at 3 volts or less in aqueous $2 \%$ sodium hydroxide and then macroetched with a $10 \%$ sodium hydroxide-10\% potassium ferricyanide solution. The specimen was viewed at $50 \times$ through a metallurgical microscope fitted with a universal petrographic stage. At least two and often four reflections, depending upon specimen orientation, were readily optimized. The overall accuracy of determining orientation was estimated to be $\pm 2 \mathrm{deg}$.

The fixture for holding the specimen in the universal petrographic stage under the metallurgical microscope could also be mounted in an Eulerian $x$-ray goniometer. Laue back-reflection $x$-ray photographs gave the same orientations with the same order of accuracy as the optical method in over a dozen cases. The x-ray method, being much slower, was used only as a check.

\section{Tensile Apparafus}

The tensile apparatus and test procedure used in this investigation have been described (Ref. 8). The furnace of the apparatus was operated at temperatures from 2500 to $5000^{\circ} \mathrm{F}$ under a vacuum of $1 \times 10^{-5}$ torr or less. Temperature was measured optically under near black-body conditions. The specimen, held in a hot-grip assembly, was heated by radiation from an induction-heated susceptor. It was soaked ten minutes at test temperature and then loaded to failure at a constant crosshead speed equivalent to a strain rate of $0.02 / \mathrm{min}$ by means of a motor-driven lead screw. Simultaneously, load and grip separation were recorded. To obtain elongation, grip separation values were corrected for shoulder sirain. 


\section{RESULTS}

\section{A. Single-Crysfal Data}

\section{Preferred Orientation}

The particular lot of doped tungsten used for the present study offers an unusual example of preferred orien-
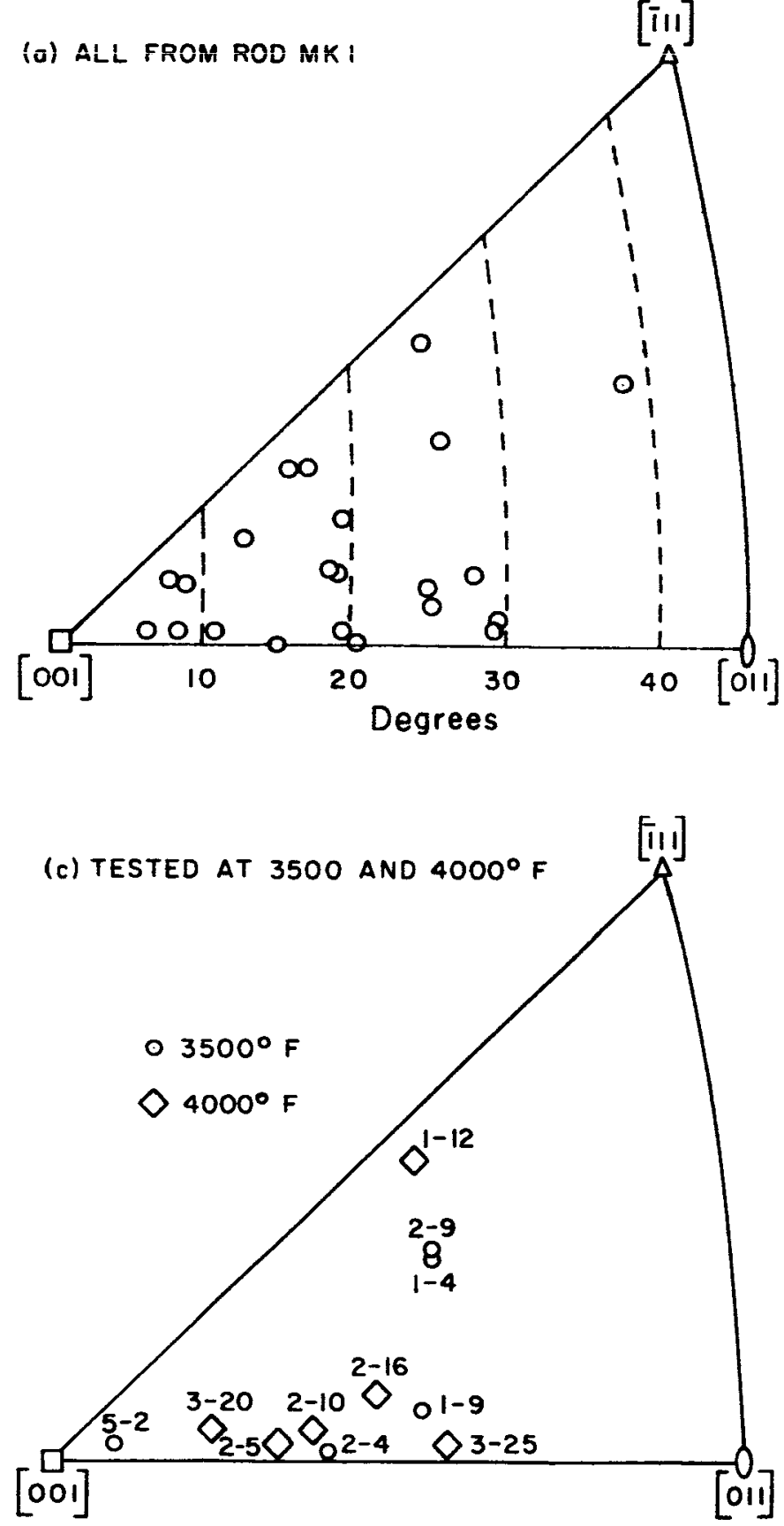

tation arising from a combination of deformation texture and recrystallization texture. As already mentioned, all but one specimen from rod MKI had single-crystal cores. The orientations of their tensile axes are shown in Fig. 2a. Orientations of all the single-crystal specimens tested,
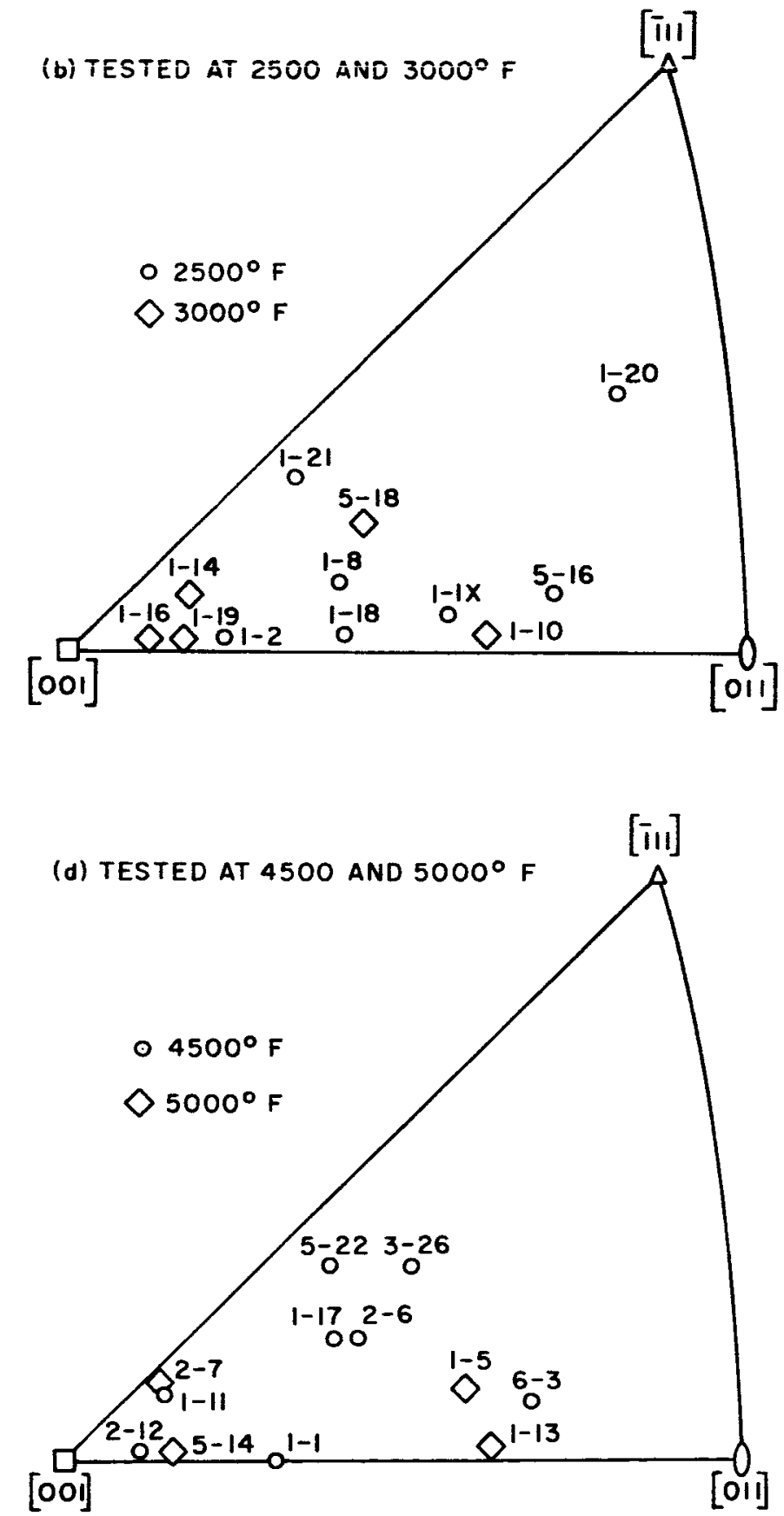

Fig. 2. Orientation of tensile axes of tungsten single-crystal specimens 
which included specimens from rods labeled MK1, 2, 3, 5, and 6, are shown in Figs. 2b, 2c, and 2d. It is apparent in Fig. 2a that the tensile axes of all but five specimens from rod MKl lie between the great circle at $10 \mathrm{deg}$ longitude and the great circle at $30 \mathrm{deg}$ longitude. The preferred orientation grouping between the 10- and 30-deg great circles also holds generally for single crystals of the other rods, as shown in Figs. 2b, 2c, and 2d. It should be noted that none of the rods exhibited the accepted [011] recrystallization texture of body-centered cubic metals (Ref. 9).

\section{Slip Systems}

The single-crystal specimens of this study were shown (Ref. 10) to deform by three families of slip, $\{110\}<111>$, $\{112\}<111\rangle$, and $\{123\}<111>$, in the temperature range from 2500 to $5000^{\circ} \mathrm{F}$. For the above three families of slip which have been observed in bcc metals, the unit triangle can be divided into regions of preferred slip based upon calculations of critical resolved shear stress (Refs. 11, 12), as given in Fig. 3a. Figure 3b shows experimentally determined slip directions for four specimens: 1-2 and 1-8 tested at $2500^{\circ} \mathrm{F}$; and $1-14$ and $1-12$ tested respectively at 3000 and $4500^{\circ} \mathrm{F}$. Circles designate the orientation of the tensile axis before slip, and arrowheads the orientation after slip. The approximate boundary areas of Fig. $3 a$ are dashed-in in Fig. 3b for reference.

Crystals 1-2 and 1-14 exhibit a phenomenon known as "overshooting" (Fig. 3b). Positions of the arrowheads indicate in each case that a critical resolved shear stress boundary has been exceeded by over $5 \mathrm{deg}$ without a change in slip direction as required by the operation of another type of family slip. Overshooting, which appears to be independent of orientation, seems to be the general case rather than the exception in tungsten single crystals in the temperature range 2500 to $5000^{\circ} \mathrm{F}$ (Ref. 10).

\section{Stress-Strain Curves}

Engineering stress-strain curves reproduced with appropriate scale factors from original $x-y$ charts are shown in Figs. 4 and 5 for crystals tested at 2500 and $4500^{\circ} \mathrm{F}$, respectively. It is of significance in Fig. 4 that crystal 1-2, whose orientation is nearest the [001] corner (Fig. 2b), has the greatest strength and ductility. The curve for this crystal is characterized by a long gradual stage III slope of the three-part generic stress-strain curve of single crystals (Ref. 13). The curve of crystal 5-16, nearest of the specimens to the [001]-[011] join and the [011] corner and which had the least strength and near-least ductility, shows a much shorter Stage III slope and an early maxi-
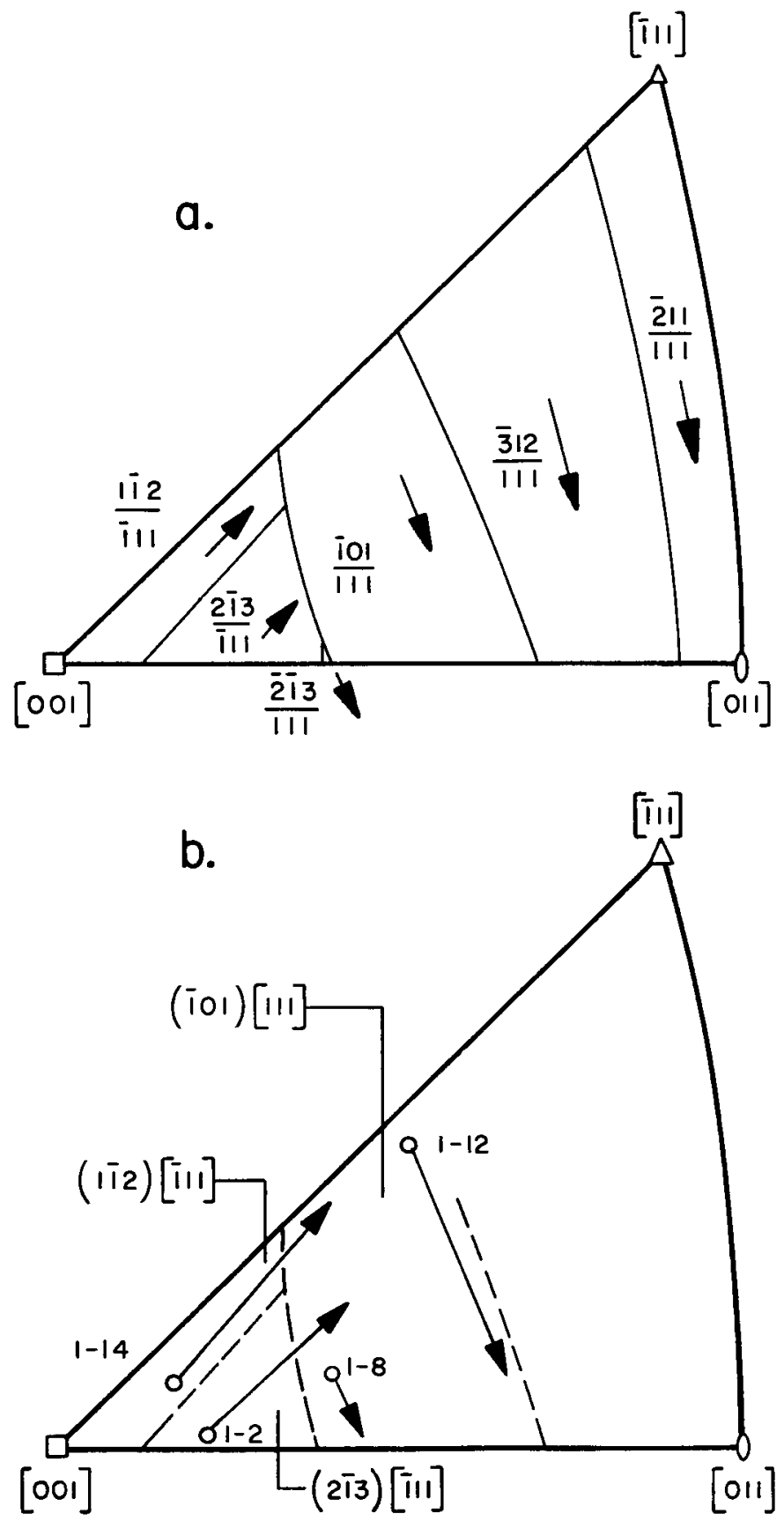

Fig. 3. Unit triangle showing (a) regions of preferred slip for three families of slip $\{110\}<111\rangle,\{112\}<111\rangle$, and $\{123\}\langle 111\rangle$, in bec metals calculated from critical resolved shear stresses (Refs. 11, 12), (b) experimentally determined slip direction

mum as compared to crystal 1-2. Except for specimen $5-16$, which has the steepest slope, the Stage II or workhardening slope of the curves of Fig. 4 shows little variation with orientation. 


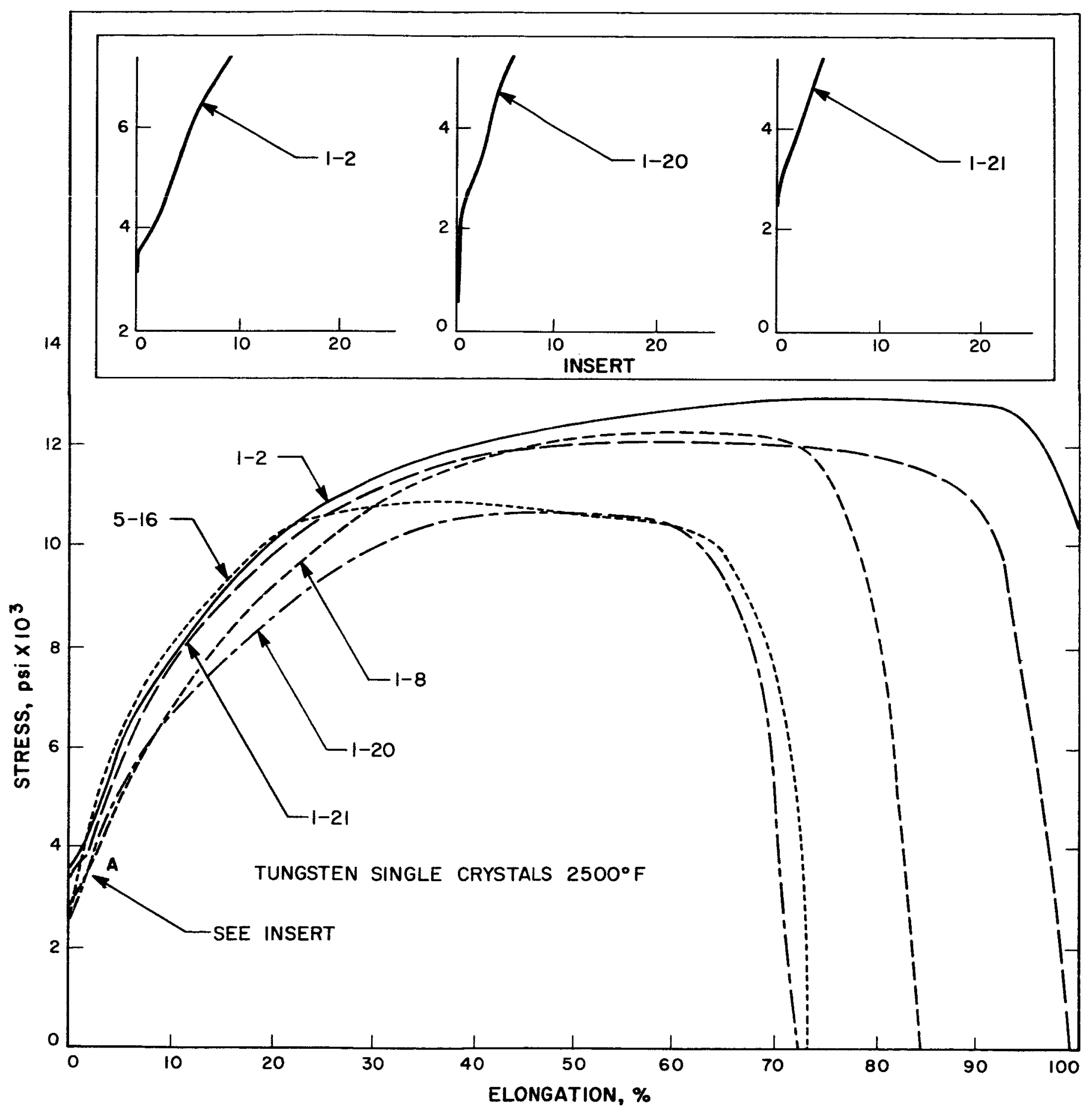

Fig. 4. Engineering stress-strain curves for tungsten single crystals deformed at $2500^{\circ} \mathrm{F}$ in tension 


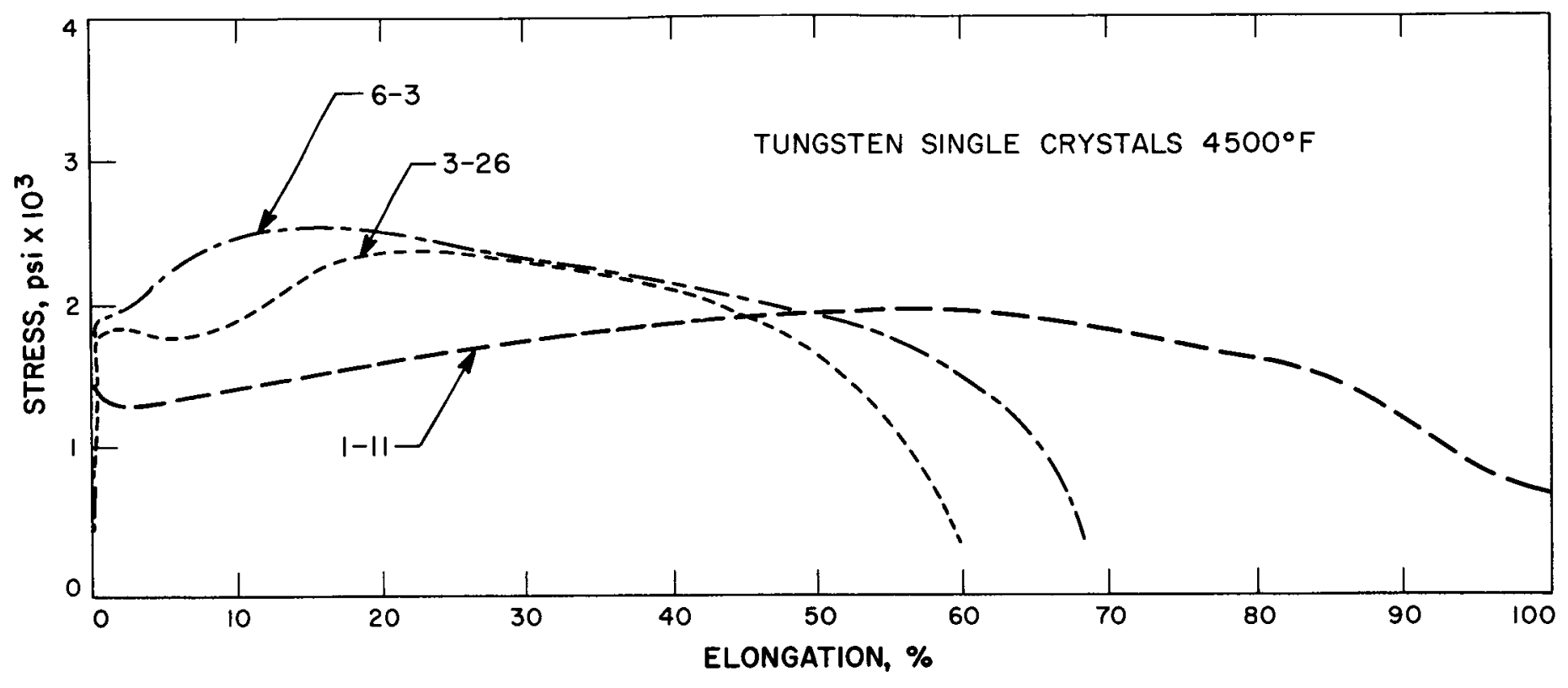

Fig. 5. Engineering stress-strain curves for tungsten single crystals deformed at $4500^{\circ} \mathrm{F}$ in tension

The insert in Fig. 4 details the beginning of the stressstrain curves for crystals 1-2, 1-21, and 1-20 and suggests the existence of a very much foreshortened Stage I slope. Although cross slip and pencil glide are believed normally to obscure the development of a full three-stage curve in bcc metals, beginning shapes slightly more pronounced than these for tungsten were observed in single-crystal niobium at 2700 and $3300^{\circ} \mathrm{F}$ (Ref. 14). The crystals showing possible Stage I behavior, 1-2, 1-21, and 1-20, have orientations which, on the basis of the boundaries of Fig. $3 \mathrm{a}$, are favorable for the occurrence of single-slip

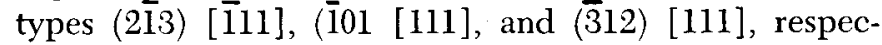
tively. Similarly, orientations favorable to single slip showed Stage I slopes in the case of niobium single crystals (Ref. 14) and $\alpha$-iron crystals at room temperature (Ref. 15). It may be, however, that an orientation favorable to extended single slip preceding conjugate slip is more important to the existence of a Stage I slope than the actual slip system.

Despite the differences in stress-strain curves of specimens tested at $2500^{\circ} \mathrm{F}$, all these specimens, observed after testing, exhibited uniform cross sections in the gage up to the point of beginning of the neck.

Curves for specimens tested at $3000^{\circ} \mathrm{F}$, not shown, were similar to those at $2500^{\circ} \mathrm{F}$ except that strengths were less and elongations greater for corresponding orientations. Curves at 3500 and $4000^{\circ} \mathrm{F}$ had shapes transitional between those at $2500^{\circ} \mathrm{F}$ and those at $4500^{\circ} \mathrm{F}$.
The stress-strain curves obtained at $4500^{\circ} \mathrm{F}$ (Fig. 5) show, as those at $2500^{\circ} \mathrm{F}$, that a specimen having an orientation close to the [001] corner, crystal 1-11, has much the greatest elongation. Changes in the shapes of the stress-strain curves for specimens tested at $4500^{\circ} \mathrm{F}$ as compared to $2500^{\circ} \mathrm{F}$ are significant. At $4500^{\circ} \mathrm{F}$ the curves for most orientations exhibit a Stage I slope and a load drop after yielding. In Fig. 5, crystals 6-3 and 3-26, oriented in the middle of the unit triangle favorably situated for (101) [111] slip, show more pronounced Stage II slopes after the load drop than does crystal 1-11, oriented near [001], which shows principally Stage I and III slopes. In specimen 6-3 the onset of Stage II hardening occurs sooner than in 3-26 because its orientation position is closer to the [001]-[011] join and it therefore undergoes less primary slip before crossing a symmetry boundary beyond which a secondary or conjugate slip system should operate. Although overshooting indicates that the secondary slip system has little immediate effect on slip direction, latent hardening on the secondary slip system does apparently occur to produce the early onset of Stage II hardening in specimen 6-3. Keh (Ref. 15), using electron transmission microscopy, observed latent hardening on a secondary slip system as the result of overshooting in $\alpha$-iron strained at room temperature.

Of the stress-strain curve features, load drop after yielding and obvious strain hardening were evident for specimens with orientations in the middle of the triangle when tested at $4000^{\circ} \mathrm{F}$, and these features persisted, but to a lesser extent, at $5000^{\circ} \mathrm{F}$. 
Although load drop after vielding is not readily explained, it may be related to the fact that during heating to test temperature a constant stress of $\simeq 250$ psi was imposed by the weight of the lower grip and pull rod. The release at the start of a test of dislocations piled up as the result of the small constant stress during heating may be similar to "work softening" (Ref. 16) which produces a load drop.

In all cases where the stress-strain curve indicated a load drop the specimens showed necking to varying degrees in a location away from the knife-edge failure, as in Fig. 6. The major axis of the elliptical cross section of the first neck remained parallel to the axis in the neck which failed, indicating that slip took place on conjugate planes.

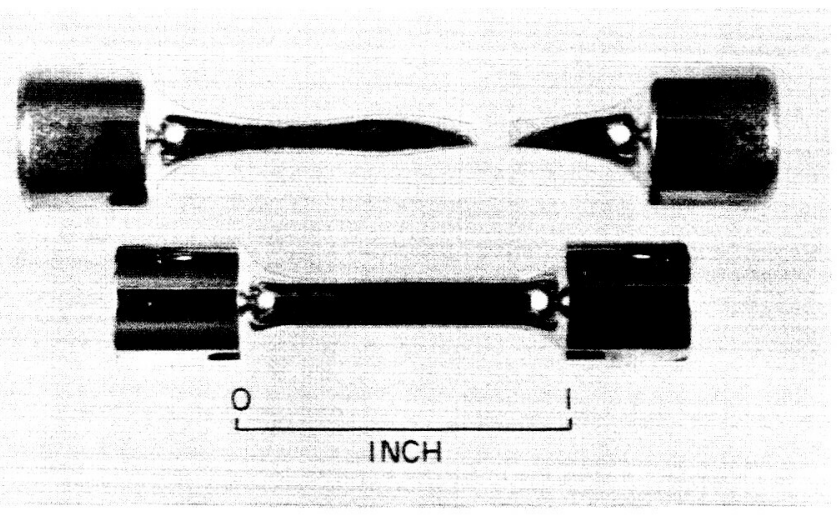

Fig. 6. Specimen 1-17 showing knife-edge failure and second neck

\section{Elongation}

The elongation of single crystals of four orientation groups in the unit triangle is shown in Figs. $7-10$ as a function of temperature. There were enough specimens in each orientation group to obtain data at nearly all the test temperatures so that altogether a fair picture of the effect of orientation and temperature on strength and ductility could be obtained.

Figure 7 shows elongation for specimens having orientations in the region near [001] within 4 deg of latitude $=3 \mathrm{deg}$, longitude $=8 \mathrm{deg}$, in which the $(1 \overline{1} 2)$ [i11] and/or the (213) [i11] slip systems have the highest resolved shear stress. No distinction in tensile behavior could be made between specimens oriented for (112) [111] and (213) [1111] slip. For example, two of the three data points in Fig. 7 at $3000^{\circ} \mathrm{F}$ represent specimens

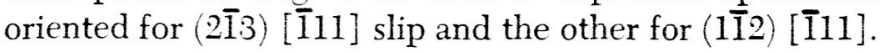

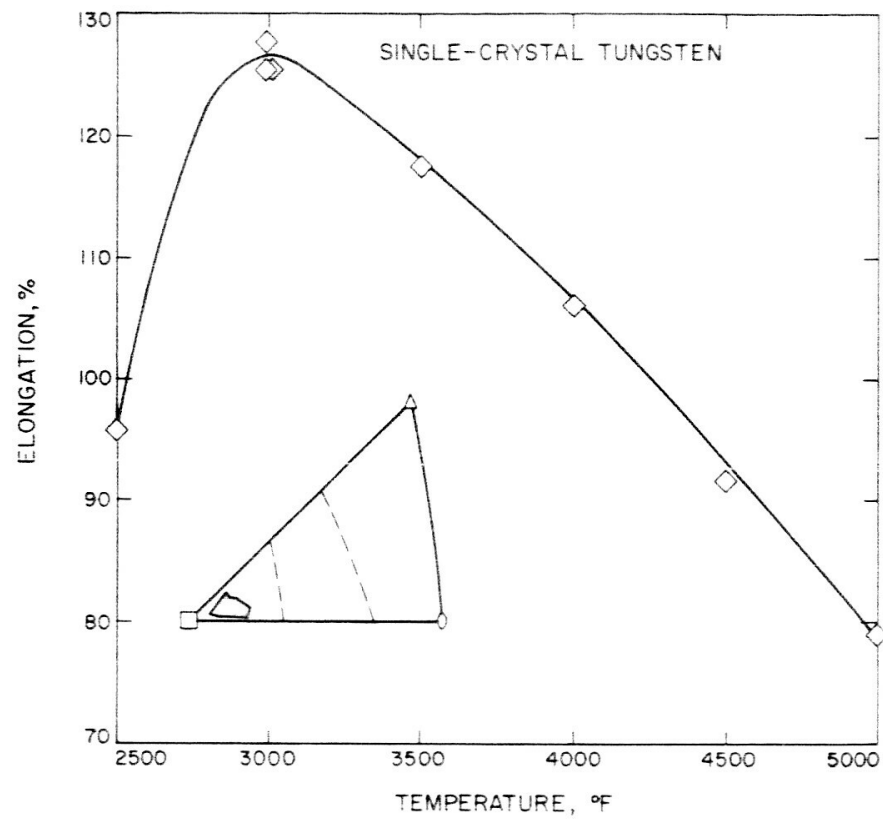

Fig. 7. Elongation of single-crystal fungsten as a function of temperature for orientations centered about latitude $=3 \mathrm{deg}$ and longitude $=8 \mathrm{deg}$ in unit triangle

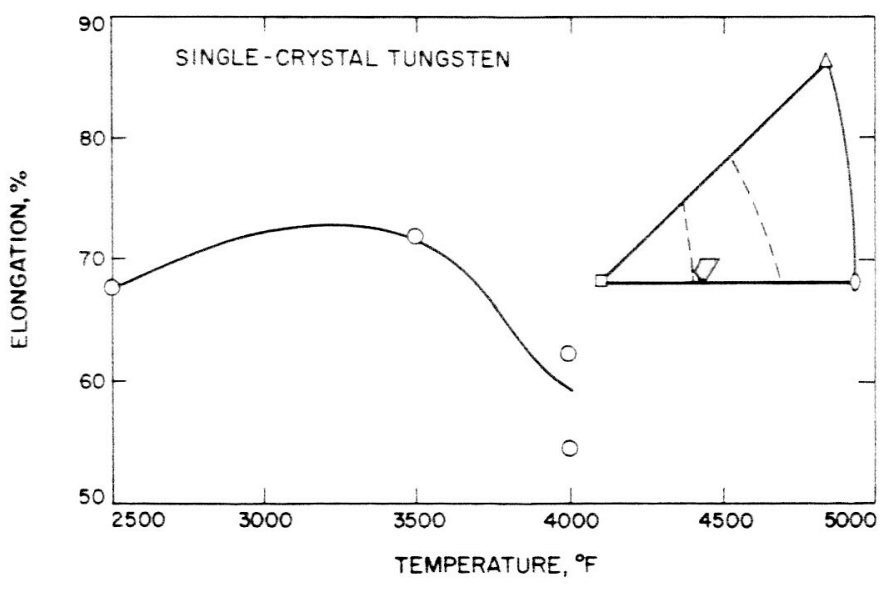

Fig. 8. Elongation of single-crystal tungsten as a function of temperature for orientations centered about latitude $=3$ deg and longitude $=20 \mathrm{deg}$ in unit triangle

In Figs. 8, 9, and 10 elongation is given for specimens clustered in orientation groups within 4 deg of latitude $=3 \mathrm{deg}$, longitude $=20 \mathrm{deg}$; latitude $=3 \mathrm{deg}$, longitude $=29 \mathrm{deg} ;$ and latitude $=14 \mathrm{deg}$, longitude $=22$ deg, respectively, all in the region where the $\{110\}$ $<111>$ family of slip has the highest resolved shear stress. 


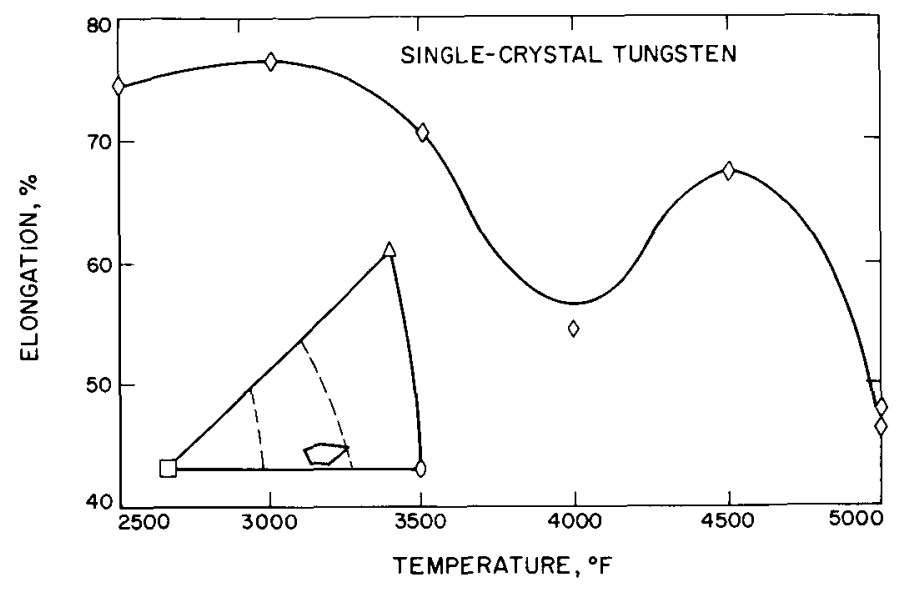

Fig. 9. Elongation of single-crystal tungsten as a function of temperature for orientations centered about latitude $=3 \mathrm{deg}$ and longifude $=29 \mathrm{deg}$ in unit triangle

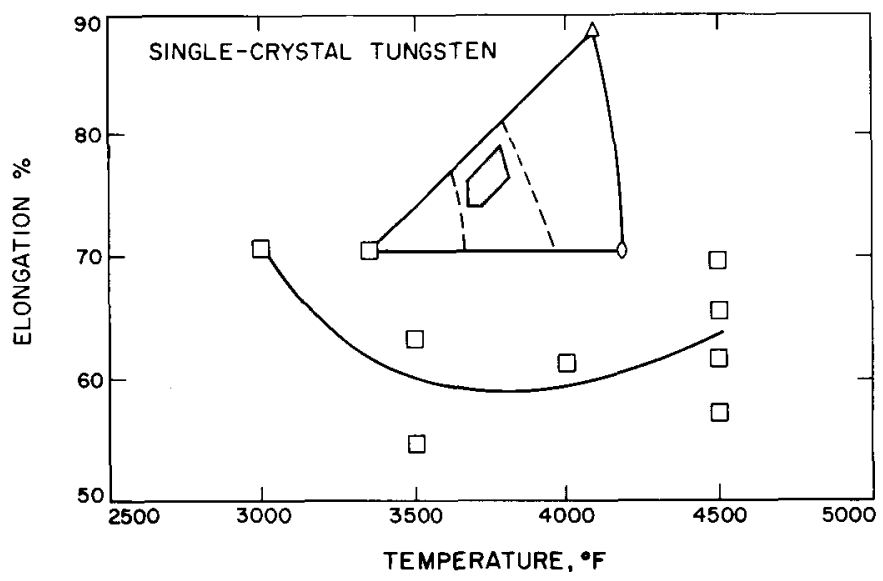

Fig. 10. Elongation of single-crystal tungsten as a function of temperature for orientations centered about latitude $=14$ deg and longitude $=22 \mathrm{deg}$ in unit triangle

It is obvious that the specimens whose orientations cluster near $[001]$ where $\{112\}<111>$ and $\{123\}<111>$ families of slip are observed have the highest elongation at all temperatures (Fig. 7). The exceptional ductility of specimens with this orientation may be related to multiple slip. For example, specimens of this orientation are the only ones which, by slipping in the [111] direction, overshoot into a region of secondary slip of another family type (Fig. 3b). Specimens of all the other orientations would undergo slip on planes of the same family, i.e., conjugate slip.
In the case of all four orientation clusters, Figs. 7-10, the greatest elongation occurs at $3000^{\circ} \mathrm{F}$, probably the result of nearly equal rates of strain hardening and recovery. It is notable that there is a minimum at $\simeq 4000^{\circ} \mathrm{F}$ and a maximum at $4500^{\circ} \mathrm{F}$ in the elongation curves representing the three orientation clusters in the $\{110\}$ $<111\rangle$ type slip region, the region in which over $50 \%$ of the specimens were oriented (Figs. 8, 9, and 10). There is little to distinguish among the elongations of any of the three clusters in this slip region.

\section{Maximum True Stress}

Maximum true stress as a function of temperature is shown in Fig. 11 for three orientation groups corresponding to the groups in Figs. 7, 8, and 9. The greatest strength is shown by the group having tensile axis orientations near [001] as mentioned in the discussion of stress-strain curves. The greater the distance of an orientation group from [001] along the [001]-[011] join in the region of $\{110\}<111\rangle$ slip, the less is its strength. The fourth orientation group at latitude $=14 \mathrm{deg}$ and longitude

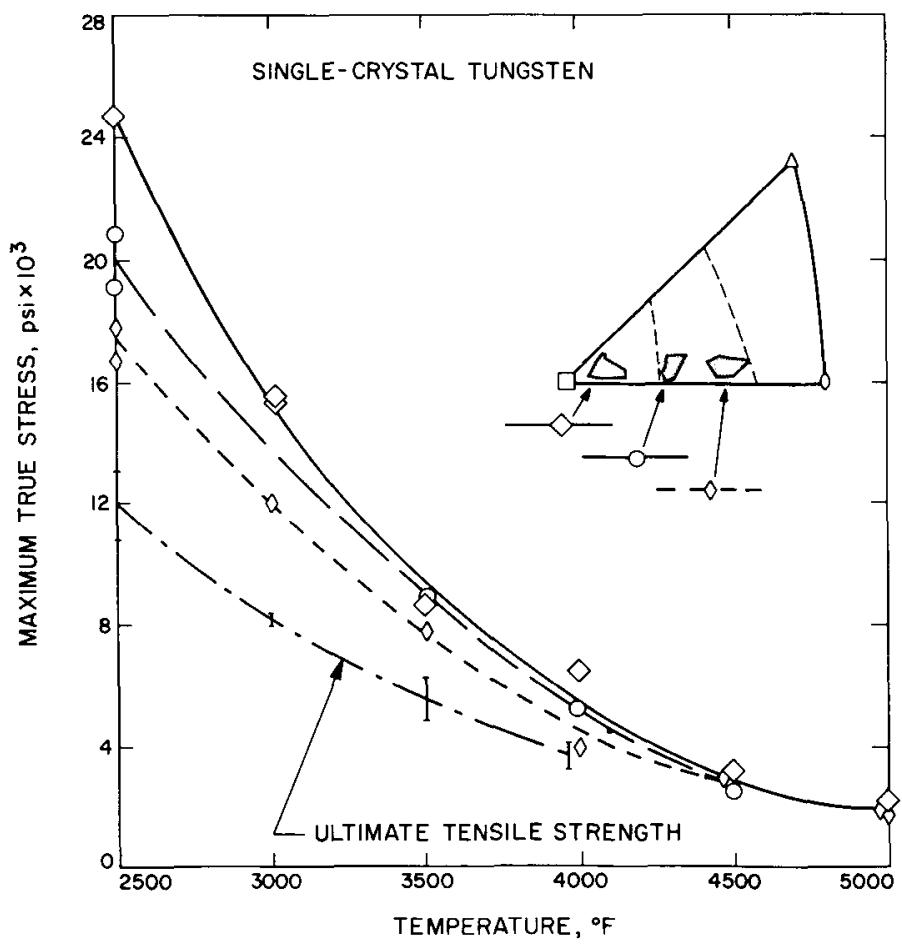

Fig. 11. Maximum true stress of single-crystal tungsten as a function of temperature for orientations centered on latifude $=3 \mathrm{deg}$ and longitude $=8 \mathrm{deg}$, latitude $=3 \mathrm{deg}$ and longitude $=20 \mathrm{deg}$, and latifude $=3 \mathrm{deg}$ and longifude $=29$ deg in unit triangle 
$=22 \mathrm{deg}$ (not plotted) was similar in strength to the third group at latitude $=3 \mathrm{deg}$ and longitude $=29 \mathrm{deg}$. Above $4000^{\circ} \mathrm{F}$, orientation has little measurable effect upon true stress. It is interesting to note in Fig. Il that at $2500^{\circ} \mathrm{F}$ the average ultimate tensile strength of all specimens tested at that temperature is less than half of the maximum true stress of those specimens having orientations near the [001] corner.

\section{Resolved Yield Stress}

No consistent variation in resolved yield stress as a function of orientation was observed. Opinsky and Smoluchowski (Ref. 12) predicted that yield stress projected (not resolved) on the [001]-[011] join should show a variation dependent upon orientation, but were unable to confirm the prediction with experiments on bcc silicon iron. In the present work resolved yield-stress values were $1000 \pm 150 \mathrm{psi}$ in the temperature range from 2500 to $3500^{\circ} \mathrm{F}$ and declined gradually with increasing temperature to $500 \pm 50 \mathrm{psi}$ at $5000^{\circ} \mathrm{F}$ for specimens of all orientations. Although no yield-stress values were found in the literature for tungsten single crystals above $2200^{\circ} \mathrm{F}$, a $0.2 \%$ offset yield of 5000 psi at $2200^{\circ} \mathrm{F}$ has been reported (Ref. 17). Assuming a Schmid factor of 0.5 , the resolved yield stress then should be 2500 psi at $2200^{\circ} \mathrm{F}$, a rather high value as compared to the value of $1000 \pm 150 \mathrm{psi}$ at $2500^{\circ} \mathrm{F}$ in the present work.

\section{Microstructure}

The microstructures of specimens tested at 3500,4000 , and $4500^{\circ} \mathrm{F}$ illustrated in Fig. $12 \mathrm{a}, 12 \mathrm{~b}$, and $12 \mathrm{c}$, respectively, are typical of specimens oriented in the middle of the unit triangle along the $[001]-[011]$ join. Sections are longitudinal ones cut normal to the knife edge, and the tensile axes lie parallel to the plane of the paper left and right. An increase in the cell size of the polygonal network is noted to result with higher test temperature.

Although large, irregular cells somewhat obscure the slip directions in Fig. 12c, they are quite apparent in Fig. 12a illustrating crystal $2-4$. The primary slip direction runs parallel to the elongated cells from the upper left-hand corner to the lower right-hand corner, and the secondary slip direction lies upper right to lower left at an angle of $\simeq 80 \mathrm{deg}$ to the primary direction. In the lower right-hand and the upper left-hand corners, making an angle of $\simeq 30 \mathrm{deg}$ with the tensile axis, there are faint deformation bands containing more or less equiaxed cells. These bands appear to be zones of interaction of the two slip systems.
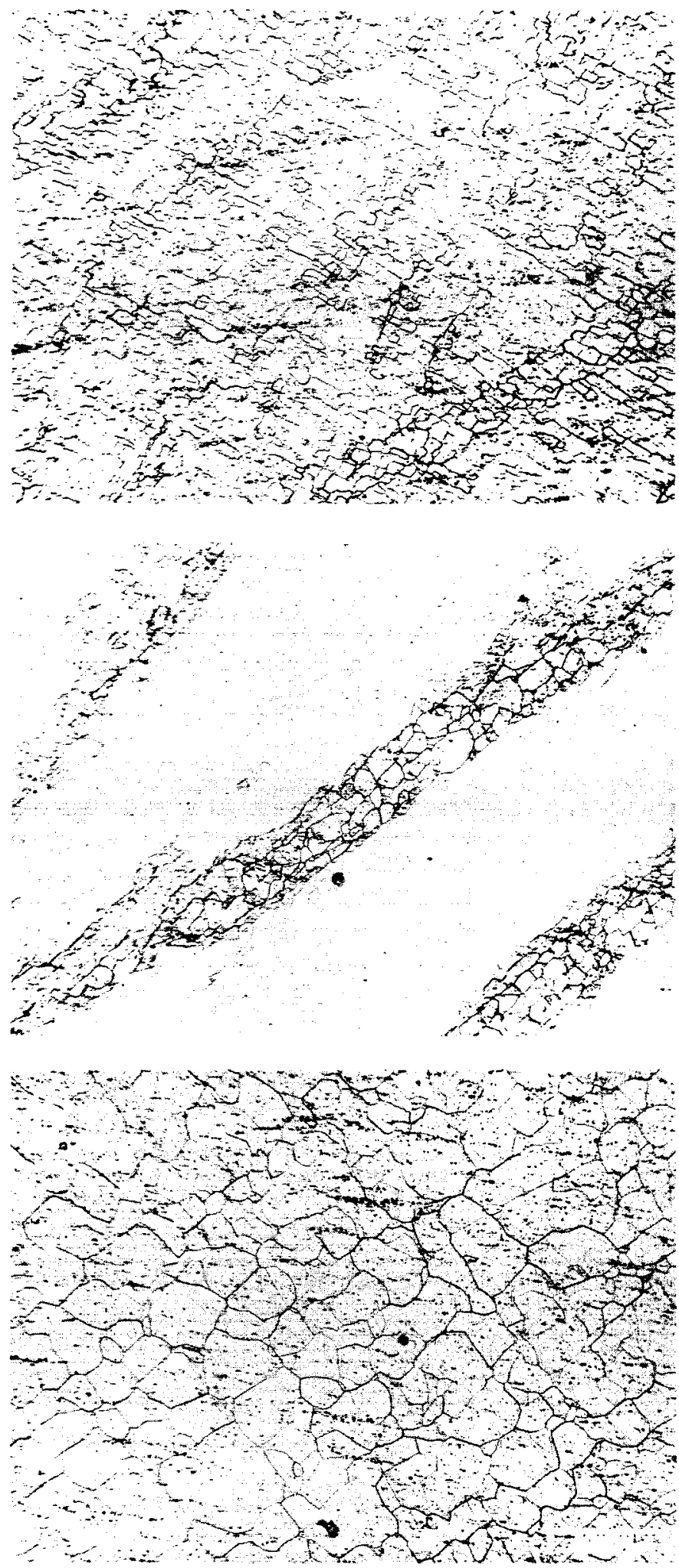

Fig. 12. Longitudinal sections of specimens fested to failure: etched $1 \mathrm{~min}$ in $30 \mathrm{~cm}^{3}$ lactic acid, $10 \mathrm{~cm}^{3} \mathrm{HNO}_{3}$, and $10 \mathrm{~cm}^{3} \mathrm{HF}$ 
The microstructure of crystal 2-10 in Fig. 12b shows well-defined deformation bands with no cellular substructure in between. This characteristic was observed only in specimens having orientations favorable to $\{110\}$ $<111>$ slip above and along the [001]-[011] join and tested at $4000^{\circ} \mathrm{F}$. Extensive overetching failed to reveal meaningful detail between the bands, and it is believed that the unusual microstructure may be related to the elongation minima noted at $4000^{\circ} \mathrm{F}$ in specimens having these orientations (Figs. 8, 9, and 10). The microstructure of specimens having orientations near [001], tested at $4000^{\circ} \mathrm{F}$, showed cellular substructure between deformation bands.

\section{B. Polycrystalline Tungsten}

Polycrystalline tungsten of the same lot and chemical composition as the single-crystal tungsten was tested under the same experimental conditions of strain rate, $0.02 / \mathrm{min}$, and temperature, 2500 to $5000^{\circ} \mathrm{F}$.

\section{Elongation and Reduction in Area}

Figure 13 shows elongation in the polycrystalline tungsten as a function of temperature with a minimum at $\simeq 3500^{\circ} \mathrm{F}$ and a maximum at $\simeq 4500^{\circ} \mathrm{F}$. The reduction-inarea curve, shown as a function of temperature in Fig. 14, also has a minimum and a maximum at approximately the same temperatures. Similar minima and maxima have been exhibited by other commercial lots of polycrystalline powder-metallurgy tungsten with a grain size in excess of $\simeq 100$ grains $/ \mathrm{mm}^{2}(0.214 \mathrm{~mm}$ dia) tested at a strain rate of $0.02 / \mathrm{min}$ (Refs, 5,6 ).

The minimum in ductility, which occurs in the temperature region $\simeq 50$ to $\simeq 65 \%$ of the homologous melting point, has been associated with grain-boundary sliding, consequent void nucleation and growth, and with impurity level and/or distribution (Ref. 5). It would now appear that the ductility minimum is associated with an additional factor related to single-crystal behavior and preferred orientation. As illustrated in Figs. 8, 9, and 10, a minimum in elongation values occurred at $\simeq 4000^{\circ} \mathrm{F}$ in single-crystal specimens having orientations $\simeq 20$ to $\simeq 30$ deg from [001] along the [001]-[011] join. Over $50 \%$ of the single crystals were oriented in this part of the region of preferred orientation. It is quite possible that a similar distribution of preferred orientations existed in the individual grains in the core of the recrystallized polycrystalline specimens inasmuch as growth of the single crystal, when it occurred, depended upon a favorably oriented "seed" crystal. Thus a relationship between preferred

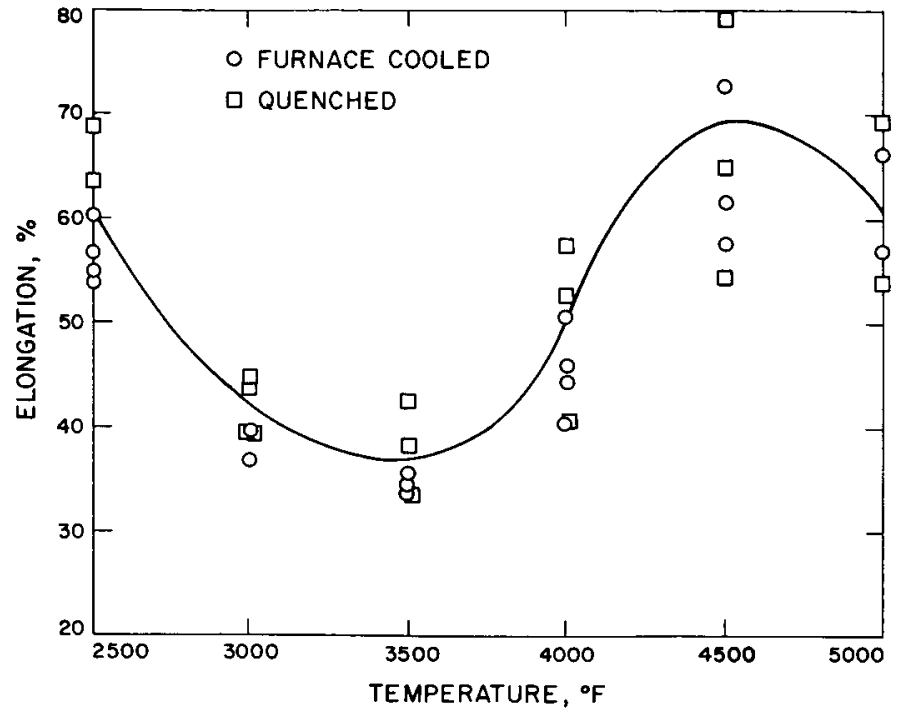

Fig. 13. Elongation of polycrystalline tungsten as a function of temperature

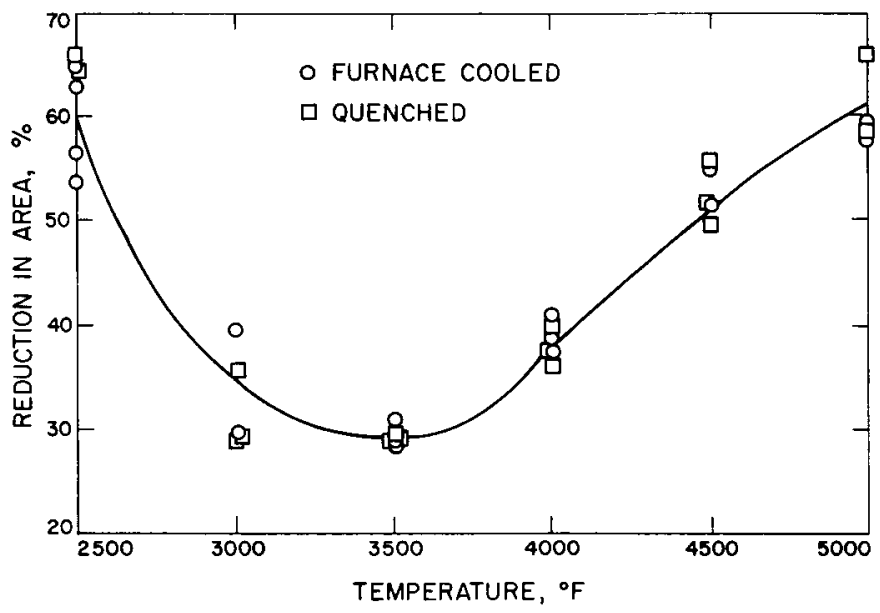

Fig. 14. Reduction in area of polycrystalline fungsten as a function of temperature

orientation in the single-crystal specimens and preferred orientation in the polycrystalline specimens is suggested, the preferred orientation having a bearing on the minimum observed in polycrystalline powder-metallurgy tungsten (Fig. 13).

The rise in values of elongation and reduction in area above the temperature region of the ductility minimum has been related to an increase in grain size (Refs. 5, 6) in polycrystalline tungsten. Again, preferred orientation may be an additional factor contributing to the rise to a maximum at $\simeq 4500^{\circ} \mathrm{F}$ in the polycrystalline tungsten. 
The ductility measurements on the present lot of powder-metallurgy tungsten doped at an intermediate level are consistent with earlier measurements. Values of elongation and reduction in area lie generally between those of undoped (Ref. 6) and fully doped (Ref. 5) polycrystalline powder-metallurgy tungsten, with the undoped material having the higher values. It is of note that ductility depends on the level of doping additives which are introduced during processing. Analyses of either the "as received" or "as recrystallized" material give little or no basis for prediction of ductility, because it is not possible to distinguish in the various tungsten materials meaningful differences in levels of elements, impurity or additive, which are at or near the limits of detection.

\section{Maximum True Stress}

Figure 15 shows the temperature dependence of maximum true stress and ultimate tensile strength in polycrystalline powder-metallurgy tungsten. The ultimate tensile strength curve for single-crystal tungsten from Fig. 11 is included to illustrate that single crystals are slightly over one-half as strong as the polycrystalline material (average grain size $\simeq 0.0585 \mathrm{~mm}$ ) at $2500^{\circ} \mathrm{F}$. The difference in strength diminishes with increasing temperature. It appears from an earlier study of undoped tungsten (Ref. 6) and the present study that an upper limit of $\simeq 2$ to 1 can be expected from the strengthening effect of grain size at temperatures of $2500^{\circ} \mathrm{F}$ and above.

\section{Cooling Rate}

Some study of cooling rate as a possible variable affecting ductility was carried out as part of this investigation. In a previous study (Ref. 6), scatter of ductility data (not reported) which was believed to result from unscheduled events such as power failure or poor vacuum during recrystallization runs suggested that differences in cooling rate might be affecting impurity level or distribution and so influencing the results. In the figures presenting polycrystalline data, Figs. 13, 14, and 15, specimens cooled in

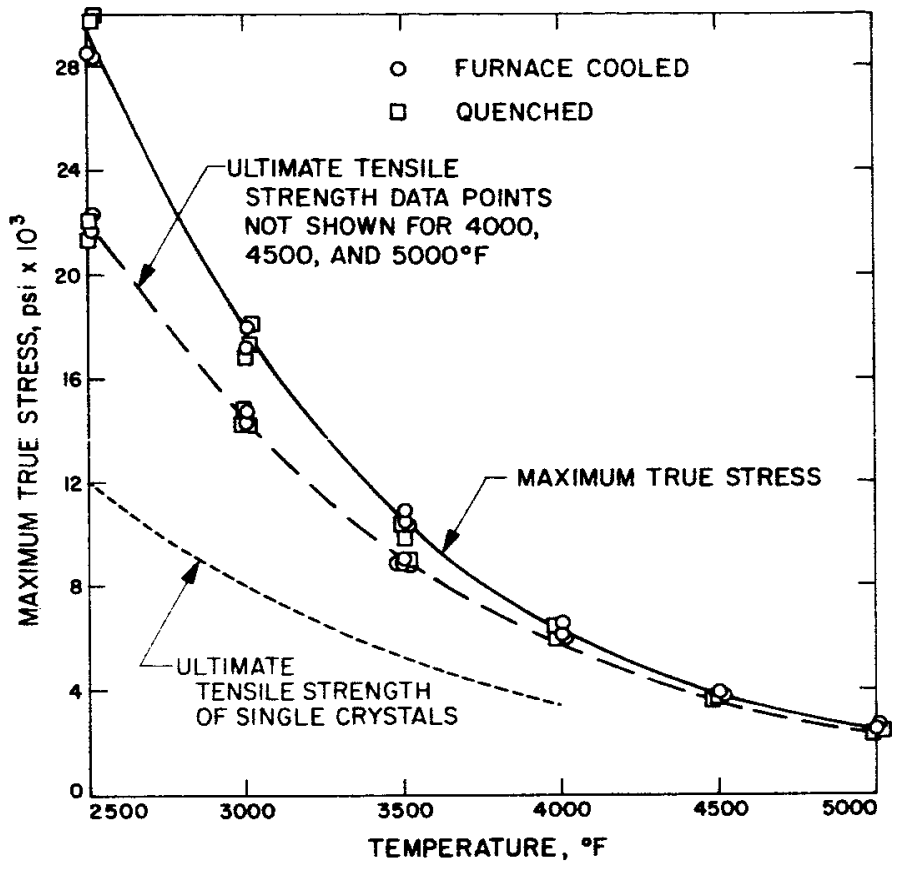

Fig. 15. Maximum true stress and ultimate tensile strength of polycrystalline fungsten as a function of temperature

the furnace following recrystallization (cooling rate of $\simeq 12^{\circ} \mathrm{F} / \mathrm{sec}$ ) are represented by circular symbols and quenched specimens (cooling rate of $\simeq 280^{\circ} \mathrm{F} / \mathrm{sec}$ ) are designated by square symbols. In Fig. 13, the elongation curve shows considerable data-point spread; however, no consistent trend differentiating quenched from furnacecooled specimens was noted. Nor could any differentiation be made in the reduction-in-area or maximum-truestress data. Schnitzel (Ref. 1) has recently found that high cooling rates after annealing at $4100^{\circ} \mathrm{F}$ affect impurity distribution and the tensile properties of zonerefined single-crystal tungsten below $1500^{\circ} \mathrm{F}$. However, quenched specimens reheated for tests above $1500^{\circ} \mathrm{F}$ showed no effect of impurities retained in solution. 


\section{CONCLUSIONS}

1. Single crystals of tungsten grown from powdermetallurgy swaged rod by annealing at $5150^{\circ} \mathrm{F}$ showed a preferred orientation. Seventy-five percent of the crystals were oriented in the unit triangle between $\simeq 10$ and $\simeq 30$ deg east longitude. The combination of deformation and recrystallization textures was not the usual [011] accepted for most bcc metals.

2. Ductility of tungsten single crystals as measured by elongation was strongly dependent on orientation at temperatures from 2500 to $5000^{\circ} \mathrm{F}$. Maximum true stress was orientation dependent from 2500 to $\simeq 4000^{\circ} \mathrm{F}$. Crystals having orientations within $\simeq 19 \mathrm{deg}$ of [001], favorably oriented for $\{112\}<111>$ and $\{123\}<111>$ family slip, were strongest and most ductile. There was no observable indication of orientation dependence in the case of resolved yield stress, values of which ranged from 1000 $\pm 150 \mathrm{psi}$ at $2500^{\circ} \mathrm{F}$ to $500 \pm 50 \mathrm{psi}$ at $5000^{\circ} \mathrm{F}$.

3. A ductility minimum at $\simeq 4000^{\circ} \mathrm{F}$ and maximum at $\simeq 4500^{\circ}$ occurred in the elongation vs. temperature curves of single crystals having orientations from $\simeq 20$ to $\simeq 30 \mathrm{deg}$ from the [001] corner in the region of preferred orientation. This minimum and maximum may relate to the minimum and maximum observed in polycrystalline tungsten through preferred orientation, presuming the polycrystalline material has a grouping of preferred orientations among the individual crystals making up the core similar to the grouping in the single-crystal tungsten.

4. At $2500^{\circ} \mathrm{F}$, stress-strain curves show steep Stage II slopes, and beginning shapes of curves for crystals oriented for extensive single slip suggest a foreshortened Stage I slope. At $4500^{\circ} \mathrm{F}$ all three stages occur for crystals having orientations in the unit triangle between $\simeq 20$ and $\simeq 30$ deg east longitude, and for specimens oriented near [001] there is little evidence of Stage II.

5. The polycrystalline to single-crystal strength ratio due to grain size effect has an upper limit of $\simeq 2: 1$ at $2500^{\circ} \mathrm{F}$ and above.

6. No effect of cooling rate following recrystallization $\left(\simeq 12\right.$ and $\simeq 280^{\circ} \mathrm{F} / \mathrm{sec}$ ) upon tensile properties of either single-crystal or polycrystalline tungsten was found.

\section{REFERENCES}

1. Schnitzel, R. H., "Deformation of Tungsten Single Crystals from $-77^{\circ}$ to $800^{\circ} \mathrm{C}$," Journal of the Less Common Metals, Vol. 8, 1965, pp. 81-89.

2. Raymond, L., and Neumann, J. P., "On the Deformation of Tungsten Single Crystals by Rolling," Transactions of the AIME, Vol. 233, August, 1965, pp. 1625-1631.

3. Sikora, P. F., and Hall, R. W., High-Temperature Tensile Properties of Wrought Sintered Tungsten, United States National Aeronautics and Space Administration, Technical Note NASA-TN-D-79, Lewis Research Center, Cleveland, 1959.

4. Sikora, P. F., and Hall, R. W., Effect of Strain Rate on Mechanical Properties of Wrought Sintered Tungsten at Temperatures Above $2500^{\circ} \mathrm{F}$, United States National Aeronautics and Space Administration, Technical Note NASA-TN-D-1094, Lewis Research Center, Cleveland, 1961.

5. Taylor, J. L., and Boone, D. H., "Tensile Properties of Tungsten from $2500^{\circ}$ to $5400^{\circ} \mathrm{F}$ in Vacuum," American Society for Metals, Transactions Quarterly, Vol. 56, No. 3, 1963, pp. 643-655, 973. 


\section{REFERENCES (Cont'd)}

6. Taylor, J. L., Boone, D. H., and Simmons, O. W., Effect of Grain Size and Impurities on Tensile Strength and Ductility of Tungsten from $2500^{\circ}$ to $5400^{\circ} \mathrm{F}$ in Vacuum, Jet Propulsion Laboratory, Technical Report No. 32-632, California Institute of Technology, Pasadena, California, July 1, 1964.

7. Federal Test Method Standard No. 151, Metals; Test Methods, United States General Services Administration, Business Service Center, Washington, D.C.

8. Taylor, J. L., "Apparatus for Tensile Testing to $5400^{\circ} \mathrm{F}$ in Vacuum," Review of Scientific Instruments, Vol. 34, No. 5, 1963, pp. 500-504.

9. Barrett, C. S., Structure of Metals; Crystallographic Methods, Principles and Data, Second Edition, New York: McGraw-Hill Book Company, 1952, p. 489.

10. Taylor, J. L., Slip in Tungsten af High Temperatures, Jet Propulsion Laboratory, Technical Report No. 32-818, California Institute of Technology, Pasadena, California, October 15, 1965.

11. Calnan, C. A., and Clews, C. J. B., "The Development of Deformation Textures in Metals-Part II. Body-Centered Cubic Metals," Philosophical Magazine, Vol. 42, 1951 (Seventh series), pp. 616-635.

12. Opinsky, A. J., and Smoluchowski, R., "The Crystallographic Aspects of Slip in Body-Centered Cubic Single Crystals. I. Theoretical Considerations," Journal of Applied Physics, Vol. 22, No. 11, 1951, pp. 1380-1384.

13. Dieter, G. E., Jr., Mechanical Metallurgy, New York: McGraw-Hill Book Company, 1961, pp. 114-115.

14. Harris, B., "Deformation of Niobium Single Crystals in the Range $1400^{\circ}-2300^{\circ} \mathrm{C}$, , Journal of the Less Common Metals, Vol. 7. 1964, pp. 185-196.

15. Keh, A. S., "Work Hardening and Deformation Sub-structure in Iron Single Crystals Deformed in Tension at $298^{\circ} \mathrm{K}$," Philosophical Magazine, Vol. 12, No. 115 , July, 1965 (Eighth series), pp. 9-30.

16. Cottrell, A. H., and Stokes, R. J., "Effects of Temperature on the Plastic Properties of Aluminum Crystals," Proceedings of the Royal Society (London), Vol. A233, 1955, p. 17.

17. Sell, H. G., King, G. W., Schnitzel, R. H., and Cerulli, N. F., Physical Metallurgy of Tungsten and Tungsten Base Alloys, United States Air Force, Wright-Patterson Air Development Center, Technical Report WADD-TR-60-37, Part V, August, 1964, Westinghouse Electric Corp., Lamp Division, Bloomfield, N.J. 
JPL TECHNICAL REPORT NO. 32-827

\section{ACKNOWLEDGMENT}

The author is appreciative of the helpful discussions with Prof. D. S. Wood of the California Institute of Technology and Prof. W. Nix of Stanford University. Of this Laboratory much credit is due K. Titus for data reduction and W. Torris and R. Ringstead for experimental work. 